\title{
Semantic-memory sources of episodic retrieval failure
}

\author{
TAKASHI KATO \\ IBM Yamato Laboratory, Yamato-shi, Japan
}

\begin{abstract}
In a cued-recall paradigm, retrieval blocking was investigated as a source of episodic retrieval failure. Each unrelated-interference (UR-I) word pair (e.g., "nurse-dollar") had its own "competitive alternative" (e.g., "doctor"), which not only was strongly related to the cue word, but also possessed the same first two letters and final letter as did the target word. None of the unrelatedcontrol (UR-C) word pairs (e.g., "clock-dollar") had such an alternative. Cued recall substantially increased from the cue-word-only (e.g., "nurse- ") to the three-letters-also cue condition (e.g., "nurse-do___r") for the UR-C but not for the UR-I word pairs. Instead, subjects frequently reported the competitive alternatives in place of the UR-I target words in the three-letters-also cue condition. It was suggested that, relying on the primary plausibility judgment, subjects falsely accepted the competitive alternatives while the UR-I target words were blocked from retrieval by the potent retrieval of these plausible alternatives.
\end{abstract}

Forgetting of information once stored in long-term memory (LTM) is assumed to be primarily or exclusively a matter of retrieval failure (e.g., Atkinson \& Shiffrin, 1968). To the extent that LTM is permanent, loss of LTM information is only temporary. In this sense, forgetting in LTM may be defined as the inability to remember something now that could be remembered at an earlier time or may be remembered at a later time.

The fundamental premise of the present research is that people fail to remember something not because they do not remember anything at all but because they remember other things. The present study presents retrieval blocking as a source of episodic retrieval failure and suggests that semantic memory plays an important role in the generation of retrieval-blocking phenomena of this sort.

Tulving (1972) first proposed a distinction between semantic and episodic memory. Semantic memory is viewed as a system that contains world knowledge, including knowledge about words and concepts, and their properties and interrelations (e.g., knowing what the "STOP" sign means). Episodic memory, on the other hand, is considered to be a system containing autobiographical information about experienced events or episodes (e.g., remembering having seen a "STOP" sign in a specific temporal-spatial context).

\footnotetext{
This article is based on a doctoral dissertation submitted to the University of California at Los Angeles in partial satisfaction of the requirements for the Doctor of Philosophy in Psychology. I am deeply indebted to Robert A. Bjork, chair of my dissertation committee, for his invaluable advice and encouragement. Thanks are also extended to Thomas D. Wickens and the members of my dissertation committee. I am grateful to James H. Neely and two anonymous reviewers for their helpful comments on an earlier draft of this article. R. A. Bjork helped coin the term "episodic reenactment" introduced in the General Discussion. Requests for reprints should be sent to Takashi Kato, Human Factors, IBM Yamato Laboratory, 1623-14 Shimotsuruma, Yamato-shi, Kanagawaken, Japan 242.
}

Retrieval blocking refers to the phenomenon that retrieval of target information is temporarily blocked by that of nontarget information (see, for similar notions, McGeoch, 1942; Roediger, 1973, 1974; Roediger \& Neely, 1982; Rundus, 1973). It has been shown that presenting some items as retrieval cues may inhibit retrieval of to-be-remembered (TBR) items (e.g., Mueller \& Watkins, 1977; Roediger, 1973, 1974, 1978; Roediger, Stellon, \& Tulving, 1977; Rundus, 1973; Slamecka, 1968, 1969; Watkins, 1975).

Watkins (1975), for example, presented subjects with lists of words belonging to common categories. In a cuedrecall test, subjects were presented with the category names and, for most of the categories, words from these categories. These words were either "intralist" (presented at encoding) or "extralist" (not presented at encoding) retrieval cues. Recall of the TBR words was found to be inhibited to essentially the same extent by either type of cue, implying that episodic properties of cues do not play an important role in the retrieval of episodic information, to say the least.

In a similar experiment, Mueller and Watkins (1977) presented subjects with both category names and intralist cues at test. In some cases, the name of the category to which the cue words belonged was the same as the presented category name, but, in other cases, there was no correspondence between the presented category name and the category from which the cue words were taken. Recall of the TBR words was inhibited only if the presented category name matched the name of the category of these cue words, indicating the importance of semantic properties of cues in episodic retrieval failure.

I suppose that what is retrieved in an episodic inquiry is primarily determined by semantic-memory properties of cues. This is thought to be due, at least in part, to the fact that semantic memory is utilized to process whatever cues available at test, including context-specifying recall 
instructions. It easily can be seen that, unless properly processed, cues would be of little impact upon episodic retrieval. It is suggested here that retrieval blocking should occur if a current retrieval cue has such semantic-memory properties that make the retrieval of nontarget information more likely than retrieval of target information. The extent of such retrieval blocking is assumed to depend upon how soon appropriate changes can be made in the current retrieval context.

Roediger and Neely (1982) defined retrieval blocks as "experiences in which target information available in the memory store is temporarily blocked from retrieval by the retrieval of closely related but erroneous information" (pp. 213-214). In the present study, however, the occurrence of retrieval blocking is assumed to be determined primarily by a relationship in semantic memory between a target item and a current retrieval cue, independently of the relationship between the target and the retrieved nontarget item. The primary purpose of the present experiments was to show that episodic retrieval of a target item would fail as a result of potent retrieval of an item strongly related to a retrieval cue but unrelated to the target item.

\section{EXPERIMENT 1}

The method involved presenting subjects with a list of cue-target study word pairs and asking them to recall the target words, given the cue words and, for half of the pairs, the first two and the final letters of the target words. Tulving and Watkins (1973) previously utilized such letter cues to investigate relationships between recall and recognition. They presented subjects with a list of 5 -letter words and later asked them to recall these words with 0 -, $2-, 3-, 4-$, or 5-letter cues. Note that the 0 - and 5-letter cue conditions are equivalent respectively to free recall and recognition. Memory performance improved as a function of the number of letters provided, except recall with 2-letter cues was not superior to free recall.

One critical manipulation in the present study concerns the use of the two types of unrelated word pairs with an important distinction. One is called the "unrelated- interference" (UR-I) word-pair type (e.g., "nurse-dollar") and the other is the "unrelated-control" (UR-C) word-pair type (e.g., "river-apple"). Each UR-I has its own "competitive alternative" (e.g., "doctor"), which not only is strongly related to the cue word, but also possesses the same first two letters and final letter as does the target. None of the UR-Cs has such a competitive alternative, however.

The second critical manipulation was made on the retrieval cues presented in a cued-recall test. In the "cue-word-only" cue condition, subjects were provided with only the cue words of the study word pairs (e.g., "nurse- ") as in a conventional cued-recall test. In the "three-letters-also" cue condition, subjects were given not only the cue words but the first two and the last letters of the targets themselves (e.g., "nurse-do___r"). See Table 1 for the description of the present experimental design.

In the present experiment, two types of related word pairs, strong associates (SAs) and moderately strong associates (MAs), were included in the study list. It was suspected that, without the presentation of any related word pairs at study, subjects would be able to reject the competitive alternatives by a simple rule that no target words were related to their cue words. It can be expected that such a higher order cue could be effective in rejecting retrieved but incorrect words, though its effectiveness in the search and retrieval of the target words is another matter. As a matter of fact, Dosher (1984) recently reported that when semantically related pairs were never presented at study, subjects were able to reject semantically related lures by rule-based "super-suppression" in a speeded recognition-memory task.

In light of the Tulving and Watkins (1973) results, the three-letters-also cues can be expected to be more effective than the cue-word-only cues. This may not be the case, however, with the retrieval of the UR-I target words. It is likely that the provision of the three-letters-also cues will lead to the potent retrieval of the competitive alternatives, thereby blocking the UR-I target words from retrieval. In the present experiment, retrieval blocking is thought to have occurred if cued recall of the UR-I target words did not increase from the cue-word-only to the

Table 1

Design Description of Experiment 1

\begin{tabular}{|c|c|c|c|}
\hline \multirow{2}{*}{$\begin{array}{l}\text { Cue-Target Semantic } \\
\text { Relationship at Study }\end{array}$} & \multicolumn{3}{|c|}{ Number of Target-Word Letters Provided at Test } \\
\hline & None & & Three \\
\hline $\begin{array}{l}\text { Unrelated- } \\
\text { Interference (UR-1) } \\
\text { (nurse-dollar) }\end{array}$ & (nurse- & ) & (nurse-do n-- $_{--}$) \\
\hline $\begin{array}{l}\text { Unrelated- } \\
\text { Control (UR-C) } \\
\text { (river-apple) }\end{array}$ & (river- & ) & (river-ap_e) \\
\hline $\begin{array}{l}\text { Strong (SA) } \\
\text { (table-chair) }\end{array}$ & (table- & ) & (table-ch__r) \\
\hline $\begin{array}{l}\text { Moderate (MA) } \\
\text { (answer-reply) }\end{array}$ & (answer- & ) & (answer-re__y) \\
\hline
\end{tabular}


three-letters-also cue condition as much as did cued recall of the UR-C target words.

\section{Method}

Subjects. Thirty-six subjects were recruited from introductory psychology classes at the University of California, Los Angeles. They were all native speakers of English and participated in the present experiment to fulfill a course requirement.

Materials and design. Forty-eight pairs of common words were used: 12 each from the UR-I, UR-C, SA, and MA word-pair types. In constructing the UR-Is, strong to moderately strong associates were first selected from the word-association norms (Jenkins, 1970; Keppel \& Strand, 1970; Miller, 1970; Postman, 1970), with the restriction that the number of letters possessed by the target words was at least five but no more than seven. This restriction was imposed in order to secure reasonable effectiveness of the three-letter cues at test.

Next, for each target word of these strong associates, a search was made through a dictionary to find an appropriate word that possessed the same first two and final letters as did the target word, but was related neither to the cue nor to the target word. One additional criterion was that this sought word should be as common a word as the target word. Then, this word replaced the target word and became the target of an unrelated word pair. With this procedure, 12 UR-Is were constructed from these strong and moderately strong associates, and the remaining ones were utilized as the SAs and the MAs.

The UR-Cs were constructed by pairing common words selected from the Paivio, Yuille, and Madigan (1968) word norms, with the restrictions that members of pairs were not related and that the number of letters possessed by the target words was from five to six, because no target words in the other three categories had more than six letters.

The word pairs were printed on cards, and booklets were made containing 48 pages of word pairs, one pair per page. Also, two memory tests were constructed, one for cued recall and one for a distractor task given between the study and the cued-recall test. Two different orders of the study word pairs were constructed according to the block randomization procedure in which each type of word pair appeared exactly once in each of the 12 blocks of four presentations.

The test sheets for cued recall listed all the cue words as retrieval cues. For exactly half of the target words in each of the four wordpair types, three-letter cues were provided as additional cues. Two different test forms were prepared so that, across the two test forms, every target word would be tested exactly once with and without its three-letter cue. The block randomization procedure was used to determine how the target words would be tested. Each type of word pair was tested exactly once, and each of the two types of cue conditions was used exactly twice in each of the blocks of four test positions with the restriction that the same type of word pair would not be tested with the same cue condition more than twice in a row.

Procedure. Subjects were run in two groups of 18 each. Each subject was given a booklet containing an instruction page and 48 pages of the study word pairs. The instructions stated that subjects would be given $10 \mathrm{sec}$ to study each word pair during which time they should study the pair as a unit regardless of whether or not the members of the pair were related. Also, it was stressed that they should neither spend more than $10 \mathrm{sec}$ for any particular pair nor proceed to the next pair before $10 \mathrm{sec}$ elapsed. By tapping a table, the experimenter signaled subjects when to proceed to the next page of the booklet.

As soon as they were finished with the study booklet, subjects were given a distractor task in which they were asked to recall and write down as many names as they could for each of the three categories: boys' names, girls' names, and the last names of United
States presidents. This semantic memory test lasted for $5 \mathrm{~min}$. Then, subjects were provided with the test sheets and instructed to recall the target words of the study word pairs using the cue words and, if present, the three-letter cues as well. Eight minutes were allowed for this cued-recall test.

\section{Results and Discussion}

Proportions of cued recall were computed as a function of the study word-pair types and the cue conditions. Also, for the UR-Is, semantic intrusions (e.g., reporting "doctor" in place of "dollar") were counted in both the cue conditions. These results are presented in Figure 1.

A within-subjects ANOVA was applied to the recall data. Note that the level of significance was set at .05 for all the tests to be reported in the present study. The ANOVA results showed that both main effects were significant [for the types of word pairs, $\mathrm{F}(3,105)=64.17$, $\mathrm{MSe}=.99$; for the cue conditions, $\mathrm{F}(1,35)=78.63$, $\mathrm{MSe}=23.51 \mathrm{]}$. Also, the interaction between the wordpair types and the cue conditions was found to be significant $[\mathrm{F}(3,105)=13.74$, MSe $=1.05]$.

The recall proportions of the four word-pair types were compared within each cue condition using a NewmanKeuls test. The results showed that under the cue-wordonly cue condition, the proportions of correct recall were significantly different from each other except those between the UR-Is and the UR-Cs $(\mathrm{MSe}=1.24)$. Under

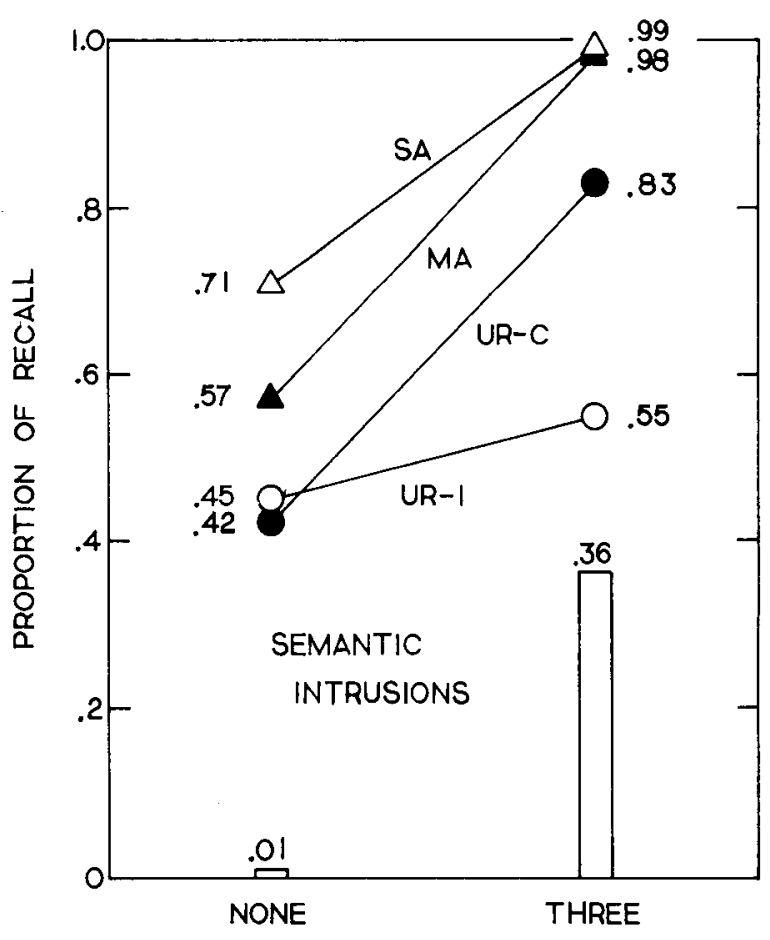

NO. OF LETTERS PROVIDED AT TEST

Figure 1. Cued recall as a function of word-pair types and cue types, and semantic intrusions of UR-Is as a function of cue types: Experiment 1. 
the three-letters-also cue condition, however, all the pairwise comparisons were significant except the comparison between the SAs and the MAs (MSe $=.81$ ).

The simple main effects of the cue conditions were tested for each of the four word-pair types. It was found that the simple main effect was significant for the UR-Cs $[\mathrm{F}(1,35)=59.33$, MSe $=3.63]$, the SAs $[\mathrm{F}(1,35)=$ $52.63, \mathrm{MSe}=1.84]$, and the $\operatorname{MAs}[\mathrm{F}(1,35)=68.48$, $\mathrm{MSe}=3.29]$, but not for the UR-Is $[\mathrm{F}(1,35)=3.55$, $\mathrm{MSe}=3.45, \mathrm{p}>.06]$. The data on the semantic intrusions for the UR-Is indicated that significantly more semantic intrusions occurred with both the cue words and the three-letter cues than with the cue words alone $[\mathrm{t}(35)=6.01]$.

With the cue words alone, subjects recalled the target words of the four word-pair types in the order expected from the association norms: the best recall for the SAs, the second best for the MAs, and then the UR-Is and the UR-Cs with no significant difference. Because the target words of the SAs are generated with high likelihood to their cue words, they should likely be recalled in the presence of these cue words.

However, the UR-Is and the UR-Cs do not have such strong relationships between members of pairs, resulting in lower likelihood of the retrieval of the target words by subjects given the cue words. There was little difference in recall between the UR-Is and the UR-Cs under the cue-word-only cue condition, because they were equivalent, as both were unrelated word pairs.

When the three-letter cues were provided in addition to the cue words, however, quite a different picture emerged. Whereas recall of the UR-Cs drastically increased, recall of the UR-Is failed to show comparable increase. The provision of three letters as cues can be expected to help recall of the UR-Cs because it effectively narrows the area of search in memory.

In the case of the UR-Is, however, the competitive alternatives more likely would be retrieved in the presence of both the cue words and the three-letter cues than in the presence of the cue words alone. The processing of "nurse" in the presence of the three-letter cue "do___r," for example, would lead to fast and potent retrieval of "doctor," thereby causing the retrieval blocking of the target word "dollar." Because strong associates were also presented at study, subjects could not use such a higher order cue that would tell them that a related word was a wrong answer. This interpretation seems to be supported by the data on the semantic intrusions for the UR-Is. There were virtually no semantic intrusions under the cue-wordonly cue condition, but quite a number of intrusions were observed under the three-letters-also cue condition.

It is suggested that the presumed benefit of the provision of the additional three-letter cues was greatly reduced for the UR-Is because of the generated retrieval blocking. Nominally, the retrieval context provided by the three-letters-also cue condition is more similar to the encoding context than is that provided by the cue-word-only cue condition. The present results, thus, indicate that it is the semantic-memory properties of cues that bring about performance difference in the retrieval of episodic information.

\section{EXPERIMENT 2}

There is one alternative interpretation of the results obtained in Experiment 1. It might be that subjects had successfully retrieved the correct target words as well as the competitive alternatives for the UR-Is but could not make a correct decision as to which was a correct answer. That is, the performance decrement, relative to the UR-C case, may be attributable to a decision problem (confusion) rather than to retrieval blocking (Bjork, 1982, personal communication).

In Experiment 2, subjects were allowed to report two responses to any cue at test. It was speculated that, if confusion had been a major factor in Experiment 1, subjects in Experiment 2 would report both the competitive alternatives and the correct target words for the UR-Is. If, on the other hand, retrieval is a real problem, they would not be able to take advantage of this opportunity.

\section{Method}

Subjects. The 16 subjects participating in this experiment were all native speakers of English and were recruited from introductory psychology courses offered at the University of California, Los Angeles. They participated in the present experiment to fulfill a course requirement. None of them had participated in Experiment 1 .

Materials and procedure. Experiment 2 used the same materials as did Experiment 1 with two changes. Two target words of the UR-Is were replaced by other words satisfying the requirements, because the old target words could be associated easily with their cue words. A change also was made on the instruction for the cuedrecall test. The added instruction stated, "If two or more words have come to your mind and you are not certain which one is correct, you may write down your second choice in the second parentheses."

Note that, in the instruction, "may" instead of "should" was used to keep an episodic-memory test situation. It was suspected that, if a second response was required or strongly suggested, subjects would be likely to treat at least some of the three-letters-also cue cases as word-completion games. As the instruction indicated, two answer spaces were provided next to each cue on the test sheets.

The procedure was identical to that in Experiment 1.

\section{Results and Discussion}

No subjects reported more than one response for any cue, making it impossible to analyze their second choices. Therefore, the data were treated the same way as in Experiment 1 to see if Experiment 2 replicated the results of Experiment 1. The results are shown in Figure 2. It can be seen that the levels of recall are quite comparable between Experiments 1 and 2. Also, comparable proportions of the semantic intrusions were obtained for the UR-Is.

The results of ANOVA showed that both main effects were significant $[\mathrm{F}(3,45)=15.62, \mathrm{MSe}=1.50$, for the word-pair types, and $\mathrm{F}(1,15)=41.87, \mathrm{MSe}=12.36$, for the cue conditions]. The interaction effect was also found to be significant $[\mathrm{F}(3,45)=8.25$, MSe $=.77]$. 


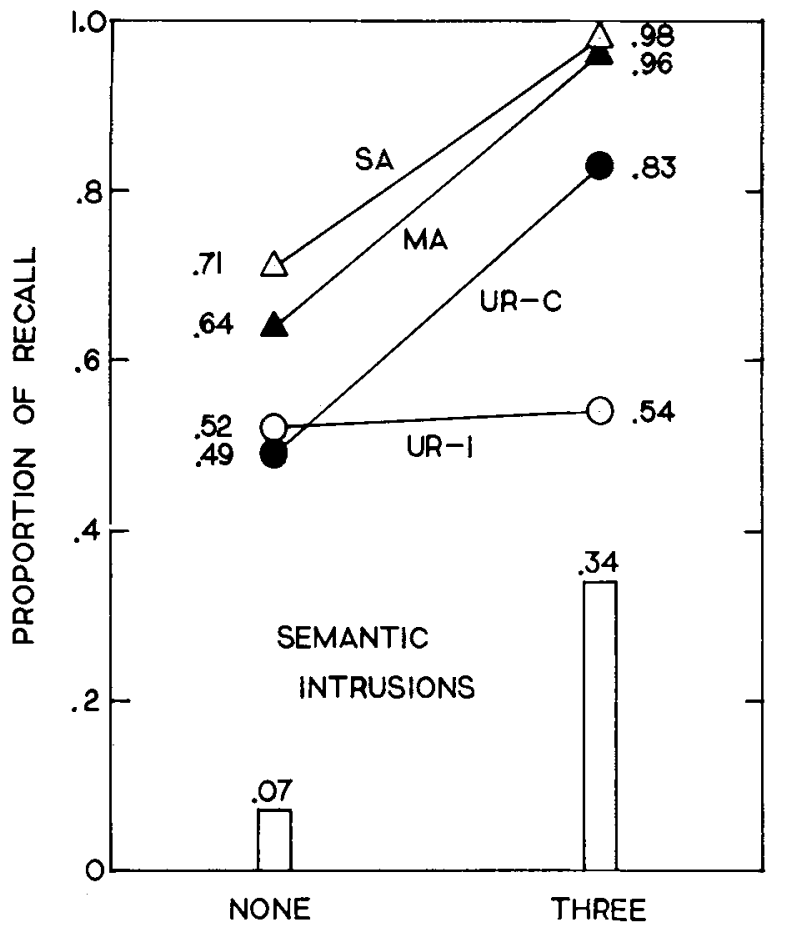

NO. OF LETTERS PROVIDED AT TEST

Figure 2. Cued recall as a function of word-pair types and cue types, and semantic intrusions of UR-Is as a function of cue types: Experiment 2.

As in Experiment 1, the simple main effect of the cue conditions was not significant for the UR-Is $[F(1,15)<1$, $\mathrm{MSe}=1.58]$, but was significant for the UR-Cs $[\mathrm{F}(1,15)$ $=48.76$, MSe $=1.40]$. However, inconsistent with Experiment 1 , there was a nonsignificant difference between the SAs and the MAs under the cue-word-only cue condition $[\mathrm{F}(1,15)=1.25, \mathrm{MSe}=3.20]$. It was found that, for the UR-Is, there were more semantic intrusions with both the cue words and the three-letter cues than with the cue words alone $[t(15)=3.99]$.

The results from Experiments 1 and 2 were subjected to a three-way ANOVA with one between-subjects factor (groups of subjects) and two within-subjects factors (word-pair types and cue conditions). The ANOVA results showed that neither the main effect of the groups nor the three-way interaction was significant $[\mathrm{F}(1,50)<1$, $\mathrm{MSe}=60.54$, for the groups, and $\mathrm{F}(3,150)<1$, $\mathrm{MSe}=.99$, for the three-way interaction].

The results in Experiment 2 closely replicated those in Experiment 1, except for the extent of the difference between the SAs and the MAs under the cue-word-only cue condition. Because the number of subjects in Experiment 1 was more than double the number in Experiment 2, the results in Experiment 1 should be taken as more representative.

Because no second choices were reported by any subjects, it seems safe to conclude that subjects did not properly retrieve the target words of the UR-Is as they made semantic intrusions. The retrieval of these target words seems to be blocked by the potent retrieval of their competitive alternatives.

As noted earlier, the instruction for the cued-recall test did not "require" or "strongly suggest" that subjects report two responses for every cue. It was suspected that the instruction otherwise would have turned the recall test into a word completion test, at least for some of the test items. The present experiment was concerned with subjects' ability to retrieve the previously presented items (i.e., episodic memory) and not with their ability to find words that fit to particular three-letter cues (i.e., semantic memory). In any case, Experiment 2 showed that subjects did not bother to write down two responses, indicating that they did not have any "compelling"' alternatives in memory.

\section{EXPERIMENT 3}

There was one additional difference between the target words of the UR-Is and the UR-Cs in Experiments 1 and 2 that was brought about by the selection procedures applied to these words. For each UR-I target word, there are at least two words that fit to its three-letter cue, because, of course, this is how the UR-I target words were constructed. However, this is not the case with most of the UR-C target words that were constructed, to some extent, by randomly pairing common words selected from the word norms with caution not to include any words having the same three letters or being related to other target words. For example, although "infant" (a UR-C target word) and "insect" fit to "in_-_t," "apple" may be the only plausible candidate for "ap__e."

It was expected that adding three letters as cues would provide subjects with "additional" assistance in recall of the target words, regardless of whether or not more than one word can fit into a particular three-letter cue. Tulving and Watkins (1973), though using different material, reported that the recall proportion increased from .24 to .56 as the number of letters provided increased from zero (i.e., free recall) to three (cf. Watkins, 1979, p. 352). They selected the words in such a manner that each word would share the same first four letters with another word, and then divided these words into two equivalent sets of single words. For instance, one group of subjects was presented with a list of words containing "grape" and "tower," and another group received a different list containing "graph" and "towel." Thus, there were at least two candidates for each of the three-letter cues such as "gra_-" and "tow_.." Yet, the results showed that recall was substantially improved with the three-letter cues.

It seems reasonable to expect, therefore, that the UR-I target words in Experiments 1 and 2 would have received the same sort of benefit if unaccompanied by their cue words at study and test. It was speculated, however, that the UR-Is would not receive as much benefit from the three-letter-cues as would the other word pairs. This is not because the three-letter-cues would not be of much 
help in themselves, but because the cue words and the three-letter cues jointly work for the retrieval of the competitive alternatives and, thus, against that of the UR-I target words.

However, as noted above, the target words of the UR-Is and the UR-Cs differ in the extent to which they can be uniquely identified by their three-letter cues. It might be that the uniqueness or identifiability of an individual threeletter cue by itself caused the differential cued recall in the three-letters-also cue condition between these two word-pair types. In terms of the discussion developed so far, it is important to show that the present cued recall is not a single function of the cue uniqueness but a joint function of the cue words and the three-letter cues. The purpose of Experiment 3 was to demonstrate that, with the cue uniqueness held constant, the two types of unrelated word pairs and the cue conditions would still interact.

\section{Method}

Subjects. Twenty-four subjects were recruited from introductory psychology courses offered at the University of California, Los Angeles. They were all native speakers of English and participated in the present experiment as a course requirement. None of them had participated in the previous experiments reported here.

Materials, design, and procedure. A set of 24 UR-Is was developed by the same procedure utilized in Experiment 1 . The 24 UR-Is were then divided into two sets of 12 each with a caution that semantic relationships would be kept to a minimum between a given target word and the other unpaired cue words within a set. The UR-Cs in one set were constructed by pairing 12 common words with the target words of the UR-Is in another set. For example, "dollar" was used as a UR-I target word in one set (i.e., "nurse-dollar") and as a UR-C target word in another set (i.e., "clock-dollar"). That is, the uniqueness of the three-letter cues was controlled by using the same target words equally often for both the UR-Is and the UR-Cs across the two sets of word pairs. See Table 2 for this design change.

Several replacements were made in the SAs and the MAs so that any strong relationships would not exist among different word pairs within a set. The associative strength of the SAs and the MAs also was controlled. According to the association norms by Keppel and
Strand (1970) and Postman (1970), the 12 SAs had associative strength of at least $10 \%$, and the 12 MAs had associative strength of at least $3 \%$ but less than $10 \%$. The two sets of the UR-Is and the UR-Cs are listed along with the SAs and the MAs in the Appendix.

The format of the cued-recall test was the same as that used in Experiment 2 with necessary changes made on some cue words and three-letter cues. Also, Experiment 3 utilized the same semanticmemory test as did Experiment 2.

Subjects were run in groups of 4-8. As they appeared, subjects were randomly assigned to one of the eight conditions made of a 2 (study sets) $\times 2$ (presentation orders) $\times 2$ (test forms) matrix. The procedure was identical to that of Experiment 2 except that subjects were given as much time as they needed to complete the cued-recall test.

\section{Results and Discussion}

The results of Experiment 3 are shown in Figure 3. For the UR-Cs, "orthographic" intrusions (e.g., reporting "letter" in place of "leader," given "weapon-leader" at study) were observed with the proportion of .13 under the threeletters-also cue condition.

A few subjects reported second choices, most of which were made under the cue-word-only cue condition. Only one second choice was observed for a UR-I under the three-letters-also cue condition. For "bitter-sw__t," one subject reported "swift" (correct target word) as the first choice and "sweet" (competitive alternative) as the second.

The results of ANOVA showed that both main effects were significant $[\mathrm{F}(3,69)=57.84, \mathrm{MSe}=1.05$, for the types of word pairs, and $F(1,23)=44.79, \mathrm{MSe}=18.23$, for the cue conditions]. Also, the interaction was found to be significant between the word-pair types and the cue conditions $[\mathrm{F}(3,69)=5.59, \mathrm{MSe}=.82]$.

The analyses of simple main effects indicated that the recall proportions of the UR-Cs, SAs, and MAs significantly increased with the addition of the three-letter cues $[\mathrm{F}(1,23)=40.93, \mathrm{MSe}=1.97$, for the UR-Cs; $\mathrm{F}(1,23)$ $=29.37, \mathrm{MSe}=2.15$, for the SAs; $\mathrm{F}(1,23)=40.93$, $\mathrm{MSe}=1.97$, for the MAs]. However, the cue condition

Table 2

Design Description of Experiment 3

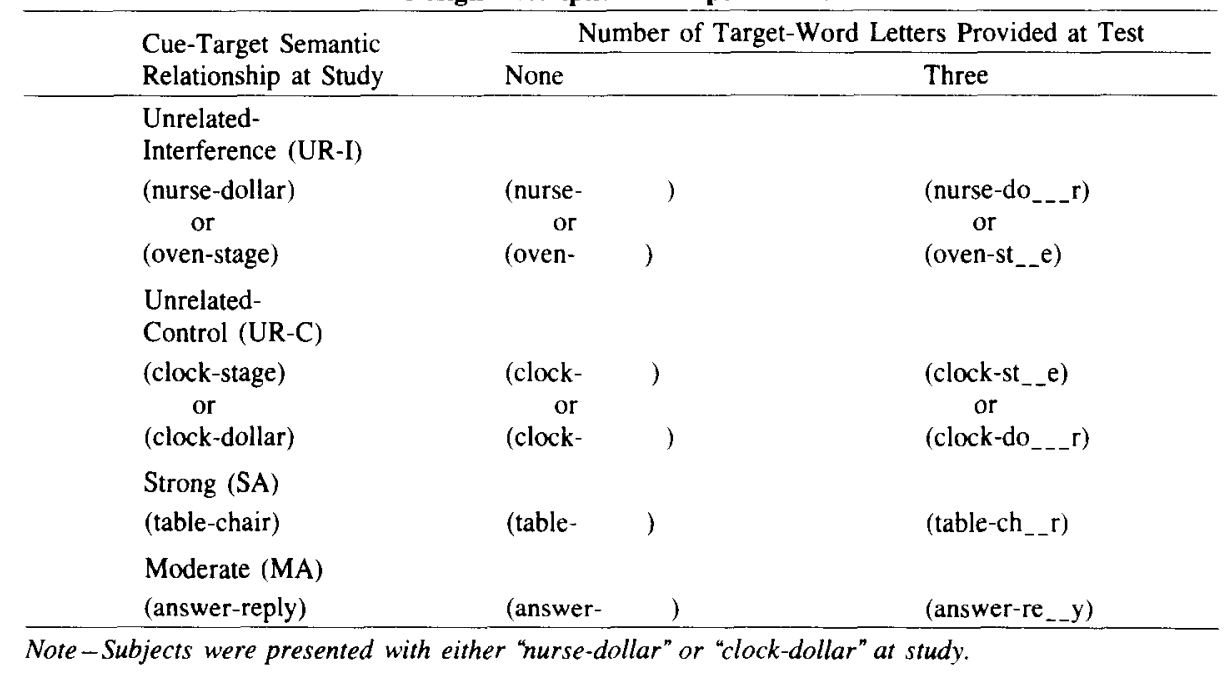




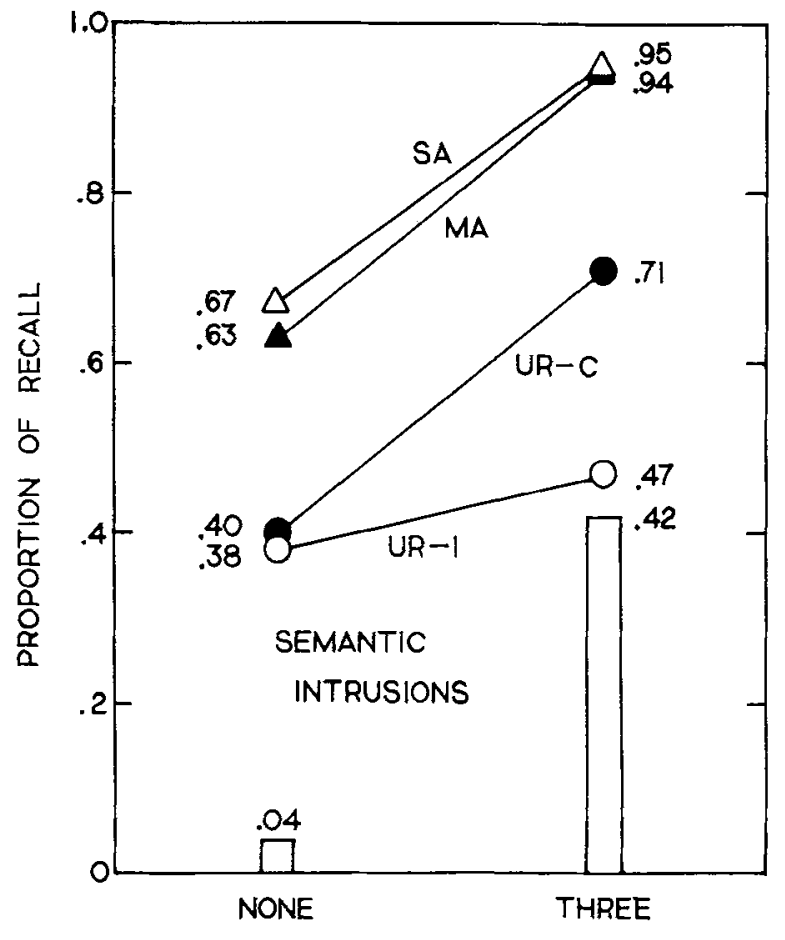

NO. OF LETTERS PROVIDED AT TEST

Figure 3. Cued recall as a function of word-pair types and cue types, and semantic intrusions of UR-Is as a function of cue types: Experiment 3.

did not significantly affect the recall levels of the UR-I target words $[\mathrm{F}(1,23)=2.08, \mathrm{MSe}=3.39, \mathrm{p}>.15]$. Although the UR-Is and the UR-Cs did not differ under the cue-word-only cue condition $[\mathrm{F}(1,23)<1$, MSe $=$ 1.45], the target words of the UR-Cs were better recalled than those of the UR-Is under the three-letters-also cue condition $[F(1,23)=25.54, \mathrm{MSe}=2.00]$. The recall levels of the SAs and the MAs were equivalent in both cue conditions.

The semantic intrusion data on the UR-Is showed that subjects made more semantic intrusions with both the cue words and the three-letter cues than with the cue words alone $[\mathrm{t}(23)=6.69]$. Also, subjects generated more semantic than orthographic intrusions under the threeletters-also cue condition $[\mathrm{t}(23)=6.63]$.

It now is clear that the interaction between the UR-I /UR-C word-pair types and the cue conditions found in Experiments 1 and 2 was not due to a material bias alone. By counterbalancing the target words of the UR-Is and the UR-Cs, it was demonstrated that significant interaction still existed between these two types of word pairs and the cue conditions.

Again, it is safe to conclude that subjects did not have any compelling second choices for the UR-Is under the three-letters-also cue condition. There was only one such response out of 144 possible responses (i.e., 24 subjects $\times 6$ items), and that subject successfully chose the target word as his first response.

The equivalent cued recall between the SAs and the MAs under the cue-word-only cue condition is inconsistent with the results obtained in Experiment 1, showing higher recall of the SAs. It seems that the differentiation of the cue-target associative strength between the SAs and the MAs in the present experiment was not large enough to produce differential cued recall between these wordpair types.

\section{GENERAL DISCUSSION}

In three cued-recall experiments, retrieval blocking was investigated as a source of episodic retrieval failure. It was predicted that episodic retrieval of a target item would fail as a result of potent retrieval of a nontarget item strongly related to a current retrieval cue but not necessarily related to the target item itself.

The consistent finding in the present experiments was that cued recall was substantially increased from the cueword-only to the three-letters-also cue condition for all the word-pair types except the UR-I. Also, subjects falsely reported the competitive alternatives in place of the target words of the UR-Is quite frequently in the three-lettersalso cue condition, but made very few of these errors in the cue-word-only cue condition.

It was suggested that, in the case of the UR-Is (e.g., "nurse-dollar"), the strong relationships between the cue words and the competitive alternatives (e.g., "nurse" and "doctor") in semantic memory made the retrieval of the competitive alternatives fast and potent in the presence of the three-letters-also cues (e.g., "nurse-do_._.r'), thereby blocking the target words from retrieval.

In the case of the UR-Cs such as "clock-dollar," however, the processing of the three-letters-also cues (e.g., "clock-do___r") did not lead to fast and potent retrieval of items fitting to the three-letter cues. Then, the three-letter cues could provide subjects with additional assistance in the search of the target words. That is, cued recall of the UR-C target words might have been increased from the cue-word-only to the three-letters-also cue condition by some additive effects of the cue words and the three-letter cues.

In the present experiment, the UR-I target words and their competitive alternatives were not semantically related (e.g., "dollar" and "doctor"), and yet the retrieval of the target words was blocked by the retrieval of the competitive alternatives. It is assumed that retrieval involves the utilization of cues, be they externally given or internally generated (e.g., Raaijmakers \& Shiffrin, 1981). When a retrieval cue is strongly related to a target item, the target will likely be retrieved as a potent response. There is ample evidence, across various experimental paradigms, that retrieval of target information can be facilitated by the provision of semantically related cues (e.g., Dong \& Kintsch, 1968; Loftus, 1973; Meyer, 
Schvaneveldt, \& Ruddy, 1975; Neely, 1977; Tulving \& Pearlstone, 1966).

When a retrieval cue is related more strongly to other items, however, the target may be among a vast number of items blocked from retrieval by the potent retrieval of the item strongly related to the current retrieval cue. It might be that the retrieved nontarget item is, in fact, semantically related to the target item blocked from retrieval (e.g., Mueller \& Watkins, 1977; Todres \& Watkins, 1981; see also Neely, Schmidt, \& Roediger, 1983). However, the present results indicate that, with regard to the occurrence of retrieval blocking, it is by no means a necessary or sufficient condition that the target item blocked from retrieval should be semantically related to the retrieved nontarget item.

It is obvious that retrieval blocking alone does not make subjects commit intrusion errors such as those found in Experiments 1-3. Retrieval blocking, by itself, can only make subjects withhold a response. In the "tip-of-thetongue" state (Brown \& McNeil, 1966), for example, subjects, though unable to retrieve with a correct answer, also do not make intrusion errors. However, the semantic intrusion data indicate that subjects were misled to accept those very items blocking the retrieval of the target items. It seems worth noting that the present semantic intrusions resemble the "updating failures" (Bjork, 1978) or the intrusion of out-of-date, to-be-forgotten information. Presenting an illustrative anecdote, Bjork (1978) suggested that out-of-date, to-be-forgotten information may be retrieved and falsely accepted (at least temporarily) in place of current information when "the local retrieval context matches the storage context of the past information better than it does the storage context of the current information" (p. 244).

We sometimes judge something as familiar or appropriate, simply because it looks familiar or sounds appropriate. Someone who looks familiar may turn out to be a total stranger, or some information that sounds appropriate may in fact be out-of-date, to-be-forgotten information. That is, "plausibility" (cf. Reder, 1982) or "naturalness" may be used as a basis of accepting something as appropriate or to-be-remembered information. I suppose that, if something is "naturally" retrieved in a particular context due to its nearly perfect match to that context, then it may appear to be highly plausible and may be accepted as such.

In the present study, 'doctor,' for example, may have appeared to be highly plausible and was mistakenly accepted as a correct response because it was naturally and easily retrieved in the context of "nurse-do _._r." Because related word pairs were also presented at study, subjects could not reject "doctor" as implausible in the present context. During this false retrieval process, "dollar" had no room because its retrieval was blocked by the potent retrieval of "doctor." In the context of "nurse- ," however, "doctor" may not appear to be plausible enough to pass the plausibility judgment, resulting in few instances of semantic intrusions. Nor is it likely that "doctor" would be as plausible in "clock-do___r" as in "nurse-do_-_r."

I speculate, however, that if, and only if, an initially retrieved item has failed the primary plausibility-judgment test, subjects would proceed to carry out "episodic reenactment" processing which involves a further search of the episodic information. This notion of episodic reenactment is similar to that of "reproductive recall" proposed by Hasher and Griffin (1978) and may be defined here as a process in which subjects retrace and reenact the processing operations carried out on the item at encoding.

I suppose that subjects utilized episodic reenactment processing in recall of the UR-Cs under the three-lettersalso cue condition. Because the three-letters-also cues were better aids in episodic reenactment processing than the cue-word-only cues, recall of the UR-Cs was improved from the cue-word-only to the three-letters-also cue condition. It seems that, in making a decision, we primarily depend upon the plausibility judgment unless some aspect of processed information signals us the necessity of more elaborative, episodic reenactment processing.

The present results on recall of the UR-Is may be accounted for by Rundus's (1973; see also Roediger, 1973, 1974) model and other similar models (e.g., Raaijmakers $\&$ Shiffrin, 1981). Four key assumptions of these models may be summarized: (1) that retrieval is determined by the associative strength between an item and a cue, (2) that retrieval is a sampling-with-replacement process, (3) that retrieval of an item in response to a cue strengthens the item's association to that cue, making the item more likely to be retrieved again, and (4) that retrieval is terminated when repeated attempts do not yield a new item.

Simply stated, the basic idea is that an item strongly related to a cue is retrieved first, and, with its association to the cue further strengthened, the item will likely. be retrieved again, thereby causing the retrieval blocking of other items. Thus, the competitive alternative "doc tor," for example, was retrieved first by the three-lettersalso cue "nurse-do___r," and as "doctor" was repeatedly retrieved, search was terminated without successful retrieval of the target word "dollar."

It is not clear, however, how these models might account for the facilitated recall of the UR-C target words under the three-letters-also cue condition. One plausible account may be that, due to the recent processing of the UR-Cs (e.g., "clock-dollar") at study, the target words (e.g., "dollar") became more accessible than orthographically similar words (e.g., "doctor") in the presence of the three-letters-also cues (e.g., "clock-do_._r" r"). If this were their choice, the models would have to explain why the recent processing of the UR-Is at study (e.g., "nurse-dollar") failed to make the UR-I target words (e.g., "dollar") more retrievable than the competitive alternatives in the presence of the three-letters-also cues.

An alternative account may state that the orthographically similar words were sometimes retrieved earlier than the UR-C target words in the presence of the three-letters- 
also cues, but that such retrieval did not increase the associative strength large enough to yield the repeated retrieval of these words. In the absence of repeated retrieval of a particular item, then, search was continued and the target was successfully retrieved. If this were the case, it would have to be explained why the retrieval of "doctor," for example, led to its repeated retrieval in the presence of "nurse-do___r"' but not of "clock-do___r". Whichever of the above accounts is chosen, the models might have to assume that semantic-memory properties of cues and targets are important determinants of episodic retrieval blocking.

Tulving (1979) claimed that

The compatibility relation between the trace and the cue, as a necessary condition of recollection of an event, is determined by specific encoding operations at the time of study and not by the properties of cues and target items, and their relations, in semantic memory. (p. 408) (see also Tulving \& Thomson, 1973 , p. 359)

On the contrary, the present results indicate that the success or failure of episodic retrieval depended on whether or not retrieval cues had such semantic properties that made the retrieval of other items more potent.

Some critics might argue that in Experiment 3 the competitive alternatives had been implicitly retrieved at encoding and stored in episodic memory. They might point to the "exception rule" of the "encoding specificity principle"' (Tulving \& Thomson, 1973), which states that the effectiveness of retrieval cues do not depend upon the properties of target items and cues in semantic memory "except insofar as these properties were encoded as a part of the trace of the event" (p. 359). It seems reasonable to assume that the competitive alternatives of the UR-Is had been implicitly retrieved at encoding, in light of what has been found in research on automatic processing (see Collins \& Loftus, 1975; Meyer \& Schvaneveldt, 1976; Neely, 1977; Posner \& Snyder, 1975). However, it also has been observed that initial, relatively automatic processing typically results in poor episodic memory of the processing itself (e.g., Jacoby, 1978; Schnur, 1977; see also Craik, 1981, for a review of other relevant studies).

Therefore, the question addressed here should be whether or not such automatic retrieval at encoding, if any, would have a substantial effect upon the retrieval of the other episodic information being sought. Specifically, in the present context, the most relevant question is whether or not the notion of automatic retrieval at encoding, by itself, is capable of accounting for the interaction found in Experiment 3 between the UR-I/UR-C word-pair types and the retrieval-cue conditions as well as the differences in the semantic-intrusion rates for the UR-Is between the two types of cue conditions.

If automatic retrieval of the competitive alternatives at encoding had been a critical factor in poorer recall of the UR-I target words under the three-letters-also cue condition, it should also have imposed a substantial impact upon the retrieval of the target words under the cue-word-only cue condition. As reported in Experiment 3, however, the UR-I target words were recalled as well as the UR-C target words under the cue-word-only cue condition.

More importantly, although there were very few semantic intrusions for the UR-Is under the cue-word-only cue condition, a large number of such intrusions were observed under the three-letters-also cue condition. Assuming that the competitive alternatives (e.g., "'doctor') were substantially processed at encoding and stored together with the cue and the target words ("nurse" and "dollar') in episodic memory, an explanation is needed as to why subjects, almost blindly making semantic intrusions in one retrieval context ("nurse-do___r"), could still refrain from making such intrusion errors in another retrieval context ("nurse-" ).

The notion that the cue effectiveness in episodic retrieval is independent of semantic properties of cues seems to have become a basis of the functional-distinction position of semantic and episodic memory (e.g., Herrmann \& Harwood, 1980; Herrmann \& McLaughlin, 1973; Kintsch, 1974; Lockhart, Craik, \& Jacoby, 1976; Tulving, 1976, 1979, 1983; Watkins \& Tulving, 1975). On the contrary, the present results indicate that the semantic-memory properties of cues determine the cue effectiveness in episodic retrieval.

It now appears that semantic memory plays a key role, not only in the encoding of incoming information, but also in the retrieval of the stored episodic information. It follows that semantic and episodic memory may not represent functionally and structurally distinct stores. Rather, memory may be viewed as a single-store system which contains both episodic and semantic information (e.g., Anderson, 1976; Anderson \& Bower, 1973; Anderson \& Ross, 1980; Dosher, 1984; McKoon \& Ratcliff, 1979; Muter, 1978). As Anderson and Ross (1980) argued, the semantic-episodic distinction may be considered more appropriately as a content distinction rather than a functional, structural one.

\section{REFERENCES}

ANDERson, J. R. (1976). Language, memory, and thought. Hillsdale, $\mathrm{NJ}$ : Erlbaum.

ANDERSON, J. R., \& BOWER, G. H. (1973). Human associative memory. Washington, DC: Winston.

ANDERSON, J. R., \& Ross, B. H. (1980). Evidence against a semanticepisodic distinction. Journal of Experimental Psychology: Human Learning \& Memory, 6, 441-466.

Atkinson, R. C., \& Shiffrin, R. M. (1968). Human memory: A proposed system and its control processes. In K. W. Spence \& J. T. Spence (Eds.), The psychology of learning and motivation: Advances in research and theory (Vol. 2). New York: Academic Press.

BJoRK, R. A. (1978). The updating of human memory. In G. H. Bower (Ed.), The psychology of learning and motivation (Vol. 12). New York: Academic Press.

Brown, R., \& McNeIL, D. (1966). The tip-of-the-tongue phenomenon. Journal of Verbal Learning \& Behavior, 5, 325-337.

Collins, A. M., \& LofTus, E. F. (1975). A spreading-activation theory of semantic processing. Psychological Review, 82, 407-428.

CraIk, F. I. M. (1981). Encoding and retrieval effects in human memory: A partial review. In A. D. Baddeley \& J. Long (Eds.), Attention and performance IX. Hillsdale, $\mathrm{NJ}$ : Erlbaum. 
Dong, T., \& Kintsch, W. (1968). Subjective retrieval cues in freerecall. Journal of Verbal Learning \& Verbal Behavior, 7, 813-816.

DOSHER, B. A. (1984). Discriminating preexperimental (semantic) from learned (episodic) associations: A speed-accuracy study. Cognitive Psychology, 16, 519-555.

Hasher, L., \& Griffin, M. (1978). Reconstructive and reproductive processes in memory. Journal of Experimental Psychology: Human Learning \& Memory, 4, 318-330.

HerrmanN, D. J., \& Harwood, J. R. (1980). More evidence for the existence of separate semantic and episodic stores in long-term memory. Journal of Experimental Psychology: Human Learning \& Memory, 6, 467-478.

HerrmanN, D. J.. \& MCLaughlin, J. P. (1973). Effects of experimental and preexperimental organization on recognition: Evidence for two storage systems in long-term memory. Journal of Experimental Psychology, 99, 174-179.

JACOBY, L. L. (1978). On interpreting the effects of repetition: Solving a problem versus remembering a solution. Joumal of Verbal Leaming \& Verbal Behavior, 17, 649-667.

Jenkins, J. J. (1970). The Minnesota word association norms. In L. Postman \& G. Keppel (Eds.), Norms of word association. New York: Academic Press.

KePpel, G.. \& STRAND, B. Z. (1970). Free-association responses to the primary purposes and other responses selected from the PalermoJenkins norms. In L. Postman \& G. Keppel (Eds.), Norms of word association. New York: Academic Press.

Kintsch, W. (1974). The representation of meaning in memory. Hillsdale, NJ: Erlbaum.

Lockhart, R. S., Craik, F. I. M., \& Jacoby, L. L. (1976). Depth of processing, recognition and recall: Some aspects of a general memory system. In $\mathrm{J}$. Brown (Ed.), Recall and recognition. London: Wiley.

LoFtus, E. F. (1973). Activation of semantic memory. American Joumal of Psychology, 86, 331-337.

MCGEOCH, J. A. (1942). The psychology of human leaming. New York: Longmans, Green.

McKoon, G., \& Ratcliff, R. (1979). Priming in episodic and semantic memory. Journal of Verbal Learning \& Verbal Behavior, 18. 463-480.

Meyer, D. E., \& Schvaneveldt, R. W. (1976). Meaning, memory structure, and mental processes. Science, 192, 27-33.

Meyer, D. E., SchvaneveldT, R. W., \& Ruddy, M. G. (1975). Loci of contextual effects on visual word-recognition. In P. M. A. Rabbit \& S. Dornic (Eds.), Attention and performance $V$. New York: Academic Press

Miller, K. M. (1970). Free-association responses of English and Australian students to 100 words from the Kent-Rosanoff word association test. In L. Postman \& G. Keppel (Eds.). Norms of word association. New York: Academic Press.

Mueller, C. W., \& Watkins. M. J. (1977). Inhibition from part-set cuing: A cue-overload interpretation. Journal of Verbal Learning \& Verbal Behavior, 16. 699-709.

MUter, P. (1978). Recognition failure of recallable words in semantic memory. Memory \& Cognition, 6, $9-12$

NeELy, J. H. (1977), Semantic priming and retrieval from lexical memory: Roles of inhibitionless spreading activation and limited capacity attention. Journal of Experimental Psichology: General. 106 226-254.

Neely, J. H., Schmidt, S. R., \& Roediger. H. L. (1983). Inhibition from related primes in recognition memory. Journal of Experimental Psychology: Learning, Memory, \& Cognition, 9. 196-211.

Paivio. A., Yullle, J. C.. \& Madigan, S. A. (1968). Concreteness. imagery, and meaningfulness values for 925 nouns. Journal of $E x$ perimental Pswchology Monograph. 76(1. Pt. 2).

Posner, M. I. \& SNyder, C. R. R. (1975). Attention and cognitive control. In R. L. Solso (Ed.). Information processing and cognition The Lovola simposium. Hillsdale, NJ: Erlbaum.

Postman. L. (1970). The California norms: Association as a function of word frequency. In L. Postman \& G. Keppel (Eds.). Norms of word association. New York: Academic Press.

RaAiJmakers, J. G., \& Shiffrin, R. M. (1981). Search of associative memory. Psychological Review, 88, 93-134.
REDER, L. M. (1982). Plausibility judgments versus fact retrieval: Alternative strategies for sentence verification. Psychological Review, 89, 250-280.

RoEdiger, H. L. (1973). Inhibition in recall from cueing with recall targets. Journal of Verbal Learning \& Verbal Behavior, 12, 644-657.

Roediger, H. L. (1974). Inhibiting effects of recall. Memory \& Cognition, 2, 261-269.

Roediger, H. L. (1978). Recall as a self-limiting process. Memory \& Cognition, 6, 54-63.

Roediger, H. L.. \& NeELy, J. H. (1982). Retrieval blocks in episodic and semantic memory. Canadian Journal of Psychology, 36, 213-242.

Roediger, H. L., Stellon, C. C., \& Tulving, E. (1977). Inhibition from part-list cues and rate of recall. Journal of Experimental Psychology: Human Learning \& Memory, 3, 174-188.

Rundus, D. (1973). Negative effects of using list items as recall cues Journal of Verbal Learning \& Verbal Behavior, 12, 43-50.

SCHNUR, P. (1977). Testing the encoding elaboration hypothesis: The effects of exemplar ranking on recognition and recall. Memory \& $\mathrm{Cog}$ nition, 5, 666-672.

SlameCKA, N. J. (1968). An examination of trace storage in free recall. Journal of Experimental Psychology, 76, 504-513.

Sl.AMECKA, N. J. (1969). Testing for associative storage in multitrial free recall. Journal of Experimental Psychology, 81, 557-560.

TODRES, A. K. \& W ATKINS, M. J. (1981). A part-set cuing effect in recognition memory. Journal of Experimental Psychologv: Human Learning \& Memory, 7, 9 [-99.

TulviNG, E. (1972). Episodic and semantic memory. In E. Tulving \& W. Donaldson (Eds.), Organization of memory. New York: Academic Press

Tulving, E. (1976). Ecphoric processes in recall and recognition. In J. Brown (Ed.), Recall and recognition. London: Wiley.

TuLving, E. (1979). Relation between encoding specificity and levels of processing. In L. S. Cermak \& F. I. M. Craik (Eds.), Levels of processing and human memory. Hillsdale, NJ: Erlbaum.

Tulving. E. (1983). Elements of episodic memory. New York: Oxford University Press.

Tulving, E., \& PeArlstone, Z. (1966). Availability versus accessibility of information in memory for words. Journal of Verbal Learning \& Verbal Behavior, 5, 381-391

Tulving, E., \& Thomson, D. M. (1973). Encoding specificity and retrieval processes in episodic memory. Psychological Review, 80 , 352-373.

Tulving, E., \& Watkins, M. J. (1973). Continuity between recall and recognition. American Journal of Psvchology, 86, 739-748.

WATkINS, M. J. (1975). Inhibition in recall with extralist "cues. " Journal of Verbal Learning \& Verbal Behavior, 14, 294-303.

WATKINS, M. J. (1979). Engrams as cuegrams and forgetting as cue overload: A cueing approach to the structure of memory. In C. R. Puff (Ed.), Memory organization and structure. New York: Academic Press.

Watkins, M. J., \& Tulving, E. (1975). Episodic memory: When recognition fails. Joumal of Experimental Psychology: General, 104, 5-38.

\begin{tabular}{|c|c|c|c|}
\hline \multicolumn{4}{|c|}{$\begin{array}{l}\text { Appendix } \\
\text { airs Used in Experiment } 3\end{array}$} \\
\hline \multicolumn{2}{|c|}{ Set A } & \multicolumn{2}{|c|}{ Set B } \\
\hline \multicolumn{4}{|c|}{ UR-Is (and competitive alternatives) } \\
\hline bitter & $\begin{array}{l}\text { swift } \\
\text { (sweet) }\end{array}$ & joy & $\begin{array}{l}\text { handy } \\
\text { (happy) }\end{array}$ \\
\hline nose & $\begin{array}{l}\text { small } \\
\text { (smell) }\end{array}$ & candle & $\begin{array}{l}\text { flute } \\
\text { (flame) }\end{array}$ \\
\hline blossom & $\begin{array}{l}\text { flavor } \\
\text { (flower) }\end{array}$ & wish & $\begin{array}{l}\text { debate } \\
\text { (desire) }\end{array}$ \\
\hline nurse & $\begin{array}{l}\text { dollar } \\
\text { (doctor) }\end{array}$ & clean & $\begin{array}{l}\text { diary } \\
\text { (dirty) }\end{array}$ \\
\hline rib & $\begin{array}{l}\text { stock } \\
\text { (steak) }\end{array}$ & tennis & $\begin{array}{l}\text { coast } \\
(\text { court })\end{array}$ \\
\hline
\end{tabular}


Set A

\begin{tabular}{|c|c|c|c|}
\hline cottage & $\begin{array}{l}\text { horse } \\
\text { (house) }\end{array}$ & door & $\begin{array}{l}\text { willow } \\
\text { (window) }\end{array}$ \\
\hline bed & $\begin{array}{l}\text { slump } \\
\text { (sleep) }\end{array}$ & rug & $\begin{array}{l}\text { carrot } \\
\text { (carpet) }\end{array}$ \\
\hline sofa & $\begin{array}{l}\text { cough } \\
\text { (couch) }\end{array}$ & oven & $\begin{array}{l}\text { stage } \\
\text { (stove) }\end{array}$ \\
\hline nail & $\begin{array}{l}\text { harbor } \\
\text { (hammer) }\end{array}$ & butter & $\begin{array}{l}\text { brand } \\
\text { (bread) }\end{array}$ \\
\hline grass & $\begin{array}{l}\text { grain } \\
\text { (green) }\end{array}$ & thief & $\begin{array}{l}\text { still } \\
\text { (steal) }\end{array}$ \\
\hline tobacco & $\begin{array}{l}\text { smile } \\
\text { (smoke) }\end{array}$ & pilot & $\begin{array}{l}\text { plate } \\
\text { (plane) }\end{array}$ \\
\hline message & $\begin{array}{l}\text { leader } \\
\text { (letter) }\end{array}$ & snow & $\begin{array}{l}\text { whale } \\
\text { (white) }\end{array}$ \\
\hline \multicolumn{2}{|c|}{ Set $A$} & \multicolumn{2}{|c|}{ Set B } \\
\hline \multicolumn{4}{|c|}{ UR-Cs } \\
\hline round & handy & round & swift \\
\hline dress & flute & dress & smile \\
\hline glory & debate & glory & flavor \\
\hline hotel & diary & hotel & harbor \\
\hline flood & coast & flood & grain \\
\hline banner & willow & banner & horse \\
\hline truck & carrot & truck & slump \\
\hline
\end{tabular}

Set A

\begin{tabular}{llll}
\hline clock & stage & clock & dollar \\
wine & brand & wine & cough \\
deep & still & deep & small \\
potato & plate & potato & stock \\
weapon & whale & weapon & leader \\
\hline & SAs & & \\
\hline thread & needle & leather & purse \\
author & writer & ground & earth \\
crowd & people & answer & reply \\
table & chair & highway & patrol \\
circus & clown & building & office \\
drink & water & dinner & supper \\
reason & think & wool & cotton \\
bug & insect & panic & fright \\
device & method & trouble & worry \\
tourist & travel & wisdom & smart \\
sickness & health & story & fable \\
paper & pencil & rough & tough \\
\hline & & & \\
& & &
\end{tabular}

(Manuscript received December 3, 1984; revision accepted for publication July 15,1985 .) 